\title{
The periglacial engine of mountain erosion - Part 1: Rates of frost cracking and frost creep
}

\author{
J. L. Andersen ${ }^{1}$, D. L. Egholm ${ }^{1}$, M. F. Knudsen ${ }^{1}$, J. D. Jansen ${ }^{2}$, and S. B. Nielsen ${ }^{1}$ \\ ${ }^{1}$ Department of Geoscience, Aarhus University, Høegh-Guldbergs Gade 2, 8000 Aarhus C, Denmark \\ ${ }^{2}$ Institute of Earth and Environmental Science, University of Potsdam, Potsdam, Germany
}

Correspondence to: J. L. Andersen (jane.lund@geo.au.dk)

Received: 30 March 2015 - Published in Earth Surf. Dynam. Discuss.: 22 April 2015

Revised: 9 September 2015 - Accepted: 22 September 2015 - Published: 6 October 2015

\begin{abstract}
With accelerating climate cooling in the late Cenozoic, glacial and periglacial erosion became more widespread on the surface of the Earth. The resultant shift in erosion patterns significantly changed the largescale morphology of many mountain ranges worldwide. Whereas the glacial fingerprint is easily distinguished by its characteristic fjords and U-shaped valleys, the periglacial fingerprint is more subtle but potentially prevails in some mid- to high-latitude landscapes. Previous models have advocated a frost-driven control on debris production at steep headwalls and glacial valley sides. Here we investigate the important role that periglacial processes also play in less steep parts of mountain landscapes. Understanding the influences of frost-driven processes in low-relief areas requires a focus on the consequences of an accreting soil mantle, which characterises such surfaces. We present a new model that quantifies two key physical processes: frost cracking and frost creep, as a function of both temperature and sediment thickness. Our results yield new insights into how climate and sediment transport properties combine to scale the intensity of periglacial processes. The thickness of the soil mantle strongly modulates the relation between climate and the intensity of mechanical weathering and sediment flux. Our results also point to an offset between the conditions that promote frost cracking and those that promote frost creep, indicating that a stable climate can provide optimal conditions for only one of those processes at a time. Finally, quantifying these relations also opens up the possibility of including periglacial processes in large-scale, long-term landscape evolution models, as demonstrated in a companion paper.
\end{abstract}

\section{Introduction}

Most of the Earth's mountain ranges show clear signs of glacial erosion, with distinct glacial landforms such as broad U-shaped valleys, hanging valleys, and cirque basins. Many of these mountain ranges have likely been thoroughly reshaped during the late Cenozoic period, where the cooling climate allowed glaciers to form or expand and erode into new parts of the landscape. Global cooling has also expanded the realm of other cold-climate processes, but their long-term influence on the shape of mountain ranges is not well understood compared to the influence of glaciers.

The steep headwall and sides of glacial valleys are examples of weathering-limited landforms where bedrock erosion may be controlled by frost activity. Previous studies have modelled the relations between temperature and frost- cracking processes in order to investigate the climatic control on frost-related debris production on steep slopes and on the distribution of threshold slopes (Hales and Roering, 2007, 2009; Scherler, 2014). These studies show a good correlation between the modelled zone of maximum frostcracking intensity and the source area of scree production in the Southern Alps (Hales and Roering, 2007, 2009), and in the Khumbu Himalaya, the base of the steepest headwalls correlates with zones of peak frost-cracking intensity, indicating frost-driven undercutting of these slopes (Scherler, 2014). Such findings together indicate that frost could be an important agent of erosion on steep mountain slopes.

It has been suggested that periglacial processes are also involved in the formation of the high and relatively smooth summit flats that characterise the alpine landscapes of, for 


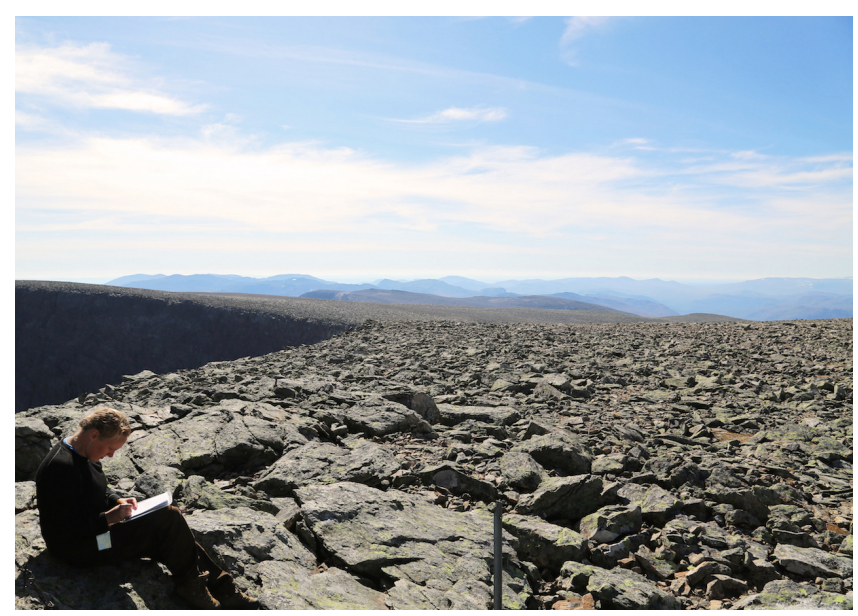

Figure 1. Low-relief summit area at Ranastongi, southern Norway, 1900 ma.s.l. Widespread sorting patterns in the debris surrounding the summit suggest periglacial processes are either actively redistributing sediment today or have done so in the past. Photo: Christian Brædstrup.

example, the Laramide ranges in the western USA and the mountains of Scandinavia, Greenland, and eastern Canada (Small and Anderson, 1998; Marquette et al., 2004; Munroe, 2006; Nielsen et al., 2009) (Fig. 1). These low-relief surfaces, which are typically covered by a thin mantle of regolith, are the focus of mass wasting and diffusive processes during ice-free periods. Furthermore, ice masses are commonly observed to be cold-based in such high-elevation settings and so tend to preserve rather than erode the underlying terrain (Briner and Swanson, 1998; Fabel et al., 2002; Stroeven et al., 2006; Goodfellow, 2007).

Using existing models to determine the periglacial influence on the summit flats is, however, not straightforward because the low-angle slopes allow sediment to accumulate. Depending on their thickness, sediments are expected to influence frost cracking of underlying bedrock in two ways: (1) sediments may retard frost cracking by dampening the propagation of surface temperature variations into the bedrock and (2) they promote frost cracking by functioning as a high-porosity water reservoir for the ice-segregation process. In order to quantify the efficiency of periglacial processes on these low-relief landforms, it is therefore vital to take a closer look at the sediment cover shielding bedrock from direct contact with the atmosphere (Anderson et al., 2012). In this study, we quantify for the first time mechanical bedrock weathering through frost cracking for a range of sediment thicknesses and mean annual air temperatures. This gives us new insights into how sediment and temperature combine to scale frost-cracking intensity.

It has long been recognised that in soil-mantled landscapes, the denudation rate is governed by the rate at which soil can be transported downslope rather than by the weathering rate of the underlying bedrock (Gilbert, 1877). When modelling periglacial processes in soil-mantled landscapes, it is therefore essential to quantify the efficiency of the active processes of sediment transport. We include an analysis of the efficiency of frost heave as a transport mechanism across a range of mean annual air temperature and sediment thickness. The quantification of both frost weathering and frostdriven transport opens the possibility of incorporating these relations into a large-scale landscape evolution model. This enables us to explore the long-term feedbacks among climate, frost-weathering intensity, sediment mobility, and the evolution of mountain topography, as shown in an accompanying paper (Egholm et al., 2015).

\section{Background}

The term "periglacial" encompasses a range of processes that involve freezing and thawing in the cold but non-glaciated realm of polar and alpine environments (French, 2013). There is still much to be learned about how these mechanisms work and on what scales (See Hall and Thorn, 2011, for a review), but here we focus on two particular processes: frost cracking and frost creep, which are both relatively well-studied via physical experiments. Frost cracking was originally attributed to volume expansion $(\sim 9 \%)$ during the freezing of water trapped in cracks and pores in the bedrock. However, more recent research has found that this mechanism requires very high levels of saturation and confinement, and the experimental focus has shifted to another process, known as ice segregation (Hallet et al., 1991; Murton et al., 2006). The ice-segregation process has long been known from studies of frost heave and creep of soils (e.g. Taber, 1929) but has also been proposed as a mechanism for breakdown of rock (Walder and Hallet, 1985, 1986). Ice segregation causes ice lenses to grow by the freezing of water that is drawn from the surrounding rock or sediment during periods of sustained subfreezing temperatures. The water migrates to the ice lenses through films of water at the grainpore interface (Rempel et al., 2004).

Information on frost cracking and frost creep comes primarily from cold-room laboratory experiments where small amounts of sediment or rock are subjected to multiple cycles of freezing and thawing (e.g. Taber, 1929; Matsuoka, 1990; Hallet et al., 1991; Murton et al., 2006). Furthermore, field monitoring has established empirical relationships between the frost-cracking process and natural temperature variations (e.g. Matsuoka, 2008; Amitrano et al., 2012; Girard et al., 2013). Several theoretical models have simulated freezing of water in porous media (Walder and Hallet, 1985; Vlahou and Worster, 2010), but only a few studies have attempted to model the spatial extent of periglacial processes in relation to climate. Anderson (1998) developed the first model relating frost cracking to climatic parameters. He introduced the concept of the frost-cracking window $(\mathrm{FCW})\left(-8\right.$ to $\left.-3^{\circ} \mathrm{C}\right)$, based on results by Walder and Hallet (1985), and quanti- 
fied frost-cracking intensity (FCI) as the length of time spent in this window during an annual temperature cycle. Hales and Roering $(2007,2009)$ extended this model by quantifying frost cracking in bedrock as a function of the temperature gradient when temperature falls within the FCW. This model, furthermore, requires that water is available in the direction of warming, which allows for continuous transport of water to the zone of frost cracking (since ice segregation causes water to flow from warm to cold areas).

Hales and Roering (2007) quantified FCI as a function of mean annual air temperature by depth-integrating frost cracking during an annual cycle. Anderson et al. (2012) extended this model by including diurnal temperature oscillations, the effect of latent heat on temperatures, a transient snow cover, a regolith layer with adjustable porosity and constant thickness $(0.4 \mathrm{~m})$, as well as limitations on water transport through frozen bedrock. The work presented here builds on these previous models and extends them by systematically delineating the effect of the thickness of the sediment cover on frost-cracking and frost-creep processes.

\section{Approach}

We present a mechanistic model that quantifies the influence of temperature and sediment cover on the two key periglacial processes: (1) the production of mobile regolith from bedrock via frost cracking and (2) the transport of sediment by frost creep. In order to provide a sensitivity analysis, we compute the intensity of FCI and the frost-heave-induced transport diffusivity $(\kappa)$ for combinations of the mean annual air temperature (MAT) and thickness of sediment overlying the bedrock $(S)$. Our approach to computing FCI and $\kappa$ is based on Anderson et al. (2012), with some important modifications.

\subsection{The heat equation}

Because frost cracking and frost creep take place within a limited temperature range, quantification of these processes requires knowledge of how changes in atmospheric temperature are propagated into the ground. We therefore solve the one-dimensional transient heat equation for the conduction of heat within the upper $20 \mathrm{~m}$ of the subsurface:

$C \frac{\partial T}{\partial t}=\frac{\partial}{\partial z}\left(k \frac{\partial T}{\partial z}\right)+H_{\mathrm{L}}$

where $T$ is temperature, $C$ is bulk volumetric heat capacity, $k$ is bulk conductivity, and $t$ is time. $H_{\mathrm{L}}$ is the latent heat release or consumption by phase change of water. We assume that the only heat exchanged in the system is caused by conductive heat flow, and we ignore the thermal effect of fluid advection. The heat equation is solved by the finiteelement method, which allows for irregular discretisation and for accurately incorporating discontinuous variations in ther-

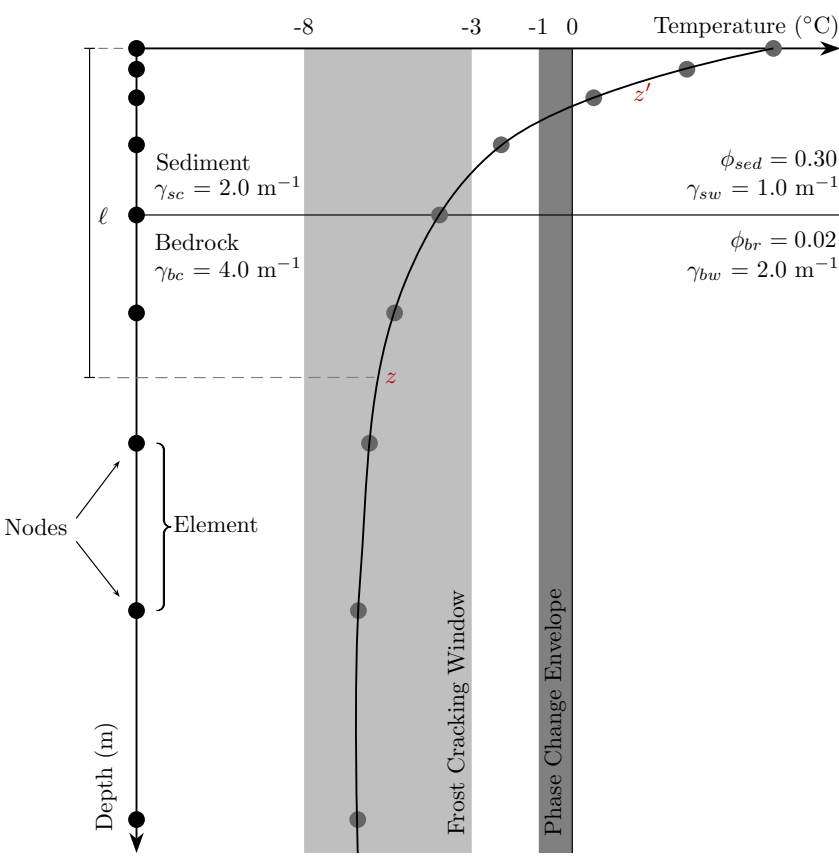

Figure 2. Schematic of the model set-up. The water volume available for frost cracking in an element at depth $z$ in the frost-cracking window is found by multiplying the porosity, $\phi$, the water fraction, $w_{\mathrm{f}}$, and the integrated flow resistance, $\Gamma$, of all elements along the path $\ell$. The integrated flow resistance from an element containing water $\left(z^{\prime}\right)$ to $z$ is found by integrating the element flow resistance $(\gamma)$ along the path between $z$ and $z^{\prime}$. The magnitude of $\gamma$ depends on the thermal state and porosity of each element. Bc: cold bedrock; bw: warm bedrock; sc: cold sediment; sw: warm sediment.

mal properties, such as that between water-saturated sediment and bedrock. We use the possibility of irregular discretisation to increase the model resolution close to the surface where the temperature gradient can be large (Fig. 2).

A constant heat flux from the Earth's interior, $q_{\mathrm{b}}$, is used as a boundary condition at the bottom of the profile $(z=20 \mathrm{~m})$. At the surface, the temperature is forced to vary annually as a sinusoidal oscillation around a given MAT with a superimposed diurnal sinusoidal variation (Fig. 3); the amplitude of the annual variation is $\mathrm{d} T_{\mathrm{a}}$, while the diurnal variation has a random amplitude between 0 and $\mathrm{d} T_{\mathrm{d}}$ (Table 1). The MAT is translated directly into ground surface temperature.

The presence of water and ice influences the thermal properties of rock and sediment, and the parameters $C$ and $k$ hence depend on porosity, $\phi$, and the unfrozen fraction of the pore space, the water fraction, $w_{\mathrm{f}}$. Based on porosity and the properties of bedrock, ice, and water, we first apply standard mixing rules (Ling and Zhang, 2004; Anderson et al., 2012) to compute the conductivity and volumetric heat capacity for the frozen $\left(k_{\mathrm{f}}\right.$ and $\left.C_{\mathrm{f}}\right)$ and the unfrozen situation $\left(k_{\mathrm{u}}\right.$ and $\left.C_{\mathrm{u}}\right)$ : 
Table 1. Model parameters. These values apply to all model results unless otherwise specified.

\begin{tabular}{lll}
\hline Symbol & Description & Value \\
\hline $\mathrm{d} T_{\mathrm{a}}$ & Amplitude of annual surface temperature variation & $8^{\circ} \mathrm{C}$ \\
$\mathrm{d} T_{\mathrm{d}}$ & Maximum amplitude of diurnal temperature variation & $4^{\circ} \mathrm{C}$ \\
$\gamma_{\mathrm{sw}}$ & Flow restriction in warm sediment & $1.0 \mathrm{~m}^{-1}$ \\
$\gamma_{\mathrm{sc}}$ & Flow restriction in cold sediment & $2.0 \mathrm{~m}^{-1}$ \\
$\gamma_{\mathrm{bw}}$ & Flow restriction in warm bedrock & $2.0 \mathrm{~m}^{-1}$ \\
$\gamma_{\mathrm{bc}}$ & Flow restriction in cold bedrock & $4.0 \mathrm{~m}^{-1}$ \\
$V_{\mathrm{cw}}$ & Critical water volume & $0.04 \mathrm{~m}$ \\
$\phi_{\mathrm{S}}$ & Porosity sediment & 0.30 \\
$\phi_{\mathrm{br}}$ & Porosity bedrock & 0.02 \\
$q_{\mathrm{b}}$ & Basal heat flow & $0.05 \mathrm{~W} \mathrm{~m}^{-2}$ \\
$k_{\mathrm{W}}$ & Conductivity water & $0.56 \mathrm{~W} \mathrm{~m}^{-1} \mathrm{~K}^{-1}$ \\
$k_{\mathrm{i}}$ & Conductivity ice & $2.14 \mathrm{~W} \mathrm{~m}^{-1} \mathrm{~K}^{-1}$ \\
$k_{\mathrm{r}}$ & Conductivity bedrock & $3.0 \mathrm{~W} \mathrm{~m}{ }^{-1} \mathrm{~K}^{-1}$ \\
$C_{\mathrm{W}}$ & Volumetric heat capacity water & $4210 \mathrm{~kJ} \mathrm{~m}^{-3} \mathrm{~K}^{-1}$ \\
$C_{\mathrm{i}}$ & Volumetric heat capacity ice & $1879 \mathrm{~kJ} \mathrm{~m}^{-3} \mathrm{~K}^{-1}$ \\
$C_{\mathrm{r}}$ & Volumetric heat capacity bedrock & $2094 \mathrm{~kJ} \mathrm{~m}^{-3} \mathrm{~K}^{-1}$ \\
$\beta$ & Frost-heave expansion coefficient & 0.05 \\
$L$ & Specific latent heat of water & $333.6 \mathrm{~kJ} \mathrm{~kg}^{-1}$ \\
$\rho_{w}$ & Density of water & $1000 \mathrm{~kg} \mathrm{~m}^{-3}$ \\
\hline
\end{tabular}

$k_{\mathrm{u}}=k_{\mathrm{w}}^{\phi} k_{\mathrm{r}}^{1-\phi}$,

$k_{\mathrm{f}}=k_{\mathrm{i}}^{\phi} k_{\mathrm{r}}^{1-\phi}$,

$C_{\mathrm{u}}=\phi C_{\mathrm{w}}+(1-\phi) C_{\mathrm{r}}$,

$C_{\mathrm{f}}=\phi C_{\mathrm{i}}+(1-\phi) C_{\mathrm{r}}$,

where $k_{\mathrm{w}}, k_{\mathrm{i}}$, and $k_{\mathrm{r}}$ are the conductivities of water, ice, and bedrock, respectively. $C_{\mathrm{w}}, C_{\mathrm{i}}$, and $C_{\mathrm{r}}$ are the volumetric heat capacities for the same three materials. We then mix these parameters according to water fraction $\left(w_{\mathrm{f}}\right)$ in order to obtain the bulk parameters:

$k=k_{\mathrm{u}}^{w_{\mathrm{f}}} k_{\mathrm{f}}^{1-w_{\mathrm{f}}}$,

$C=w_{\mathrm{f}} C_{\mathrm{u}}+\left(1-w_{\mathrm{f}}\right) C_{\mathrm{f}}$.

The effects of latent heat, $H_{\mathrm{L}}$, can be simulated by increasing the volumetric heat capacity if the pore water is in the process of changing phase (Ling and Zhang, 2004). Equation (1) is then replaced by the simplification:

$\widetilde{C} \frac{\partial T}{\partial t}=\frac{\partial}{\partial z}\left(k \frac{\partial T}{\partial z}\right)$

with

$\widetilde{C}= \begin{cases}C+\frac{\phi \rho_{\mathrm{w}}}{\mathrm{d} T_{\mathrm{L}}} L & \text { for } 0<w_{\mathrm{f}}<1 \\ C & \text { else }\end{cases}$

where $L$ is the specific latent heat of water and $\mathrm{d} T_{\mathrm{L}}$ is the width of the temperature window in which phase changes occur. We follow this strategy and increase the heat capacity in elements where freezing or thawing occur based on the following criteria:

freezing: $\quad T<0^{\circ} \mathrm{C}$ and $w_{\mathrm{f}}>0$;

thawing: $\quad T>-1{ }^{\circ} \mathrm{C}$ and $w_{\mathrm{f}}<1$.

Note that the two criteria are overlapping if $-1{ }^{\circ} \mathrm{C}<T<$ $0^{\circ} \mathrm{C}$ and $0<w_{\mathrm{f}}<1$. In this case, both freezing and thawing may occur depending on the sign of $H_{\mathrm{L}}$. We compute $H_{\mathrm{L}}$ by combining Eqs. (1) and (8),

$H_{\mathrm{L}}=(C-\widetilde{C}) \frac{\partial T}{\partial t}$

and relate this to water fraction by considering the heat involved in freezing and thawing:

$\frac{\partial w_{\mathrm{f}}}{\partial t}=-\frac{H_{\mathrm{L}}}{\phi \rho_{\mathrm{W}} L}=\frac{1}{\mathrm{~d} T_{\mathrm{L}}} \frac{\partial T}{\partial t}$.

The water fraction of each element can now be updated by the integration of Eq. (13).

The effect of latent heat is clear from the evolution of the thermal profiles, mainly because latent heat exchange stalls the propagation of temperature changes around $0{ }^{\circ} \mathrm{C}$. The effect is strongest when the porosity is high, for example in the case where bedrock is covered by a thick layer of porous sediment (Fig. 3).

\subsection{Quantifying frost-cracking intensity}

Our model for frost cracking is based on ice-segregation theory (see Murton et al., 2006; Vlahou and Worster, 2010, for 

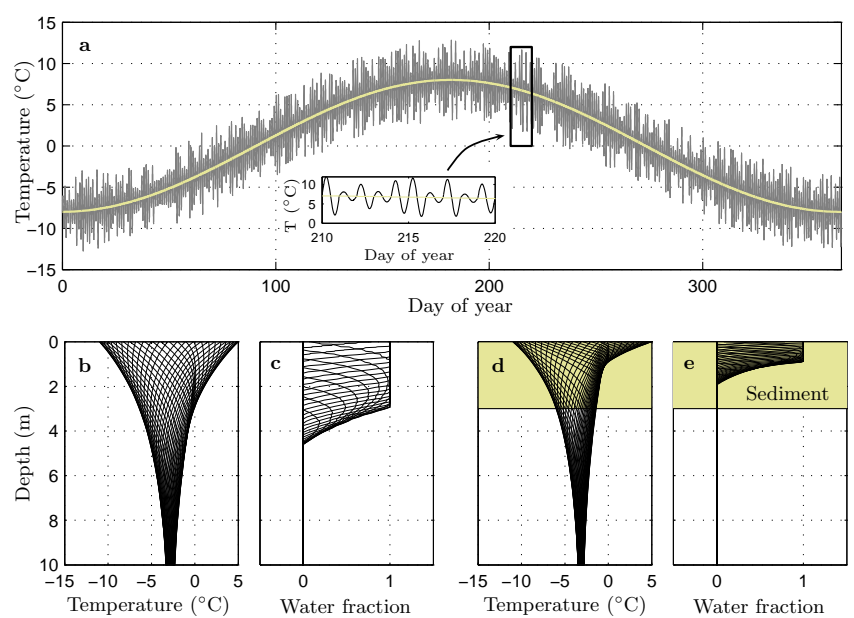

Figure 3. Panel (a): the temperature curve used as the surface boundary condition for the heat equation. The curve is a sinusoidal annual temperature oscillation of amplitude $\mathrm{d} T_{\mathrm{a}}=8^{\circ} \mathrm{C}$. Superimposed on this curve are diurnal sinusoidal variations of random amplitude between 0 and $4{ }^{\circ} \mathrm{C}$. The inset shows details of the two superimposed variations. Panel (b): modelled temperature profiles shown at weekly intervals throughout a year. The diurnal oscillations are in this case omitted for clarity. Latent heat exchange stalls the propagation of temperature variations, and this leads to a kink in the temperature profiles around $0^{\circ} \mathrm{C}$. Panel (c): the corresponding weekly evolution of water fraction along the profile. A water fraction of 0 corresponds to frozen conditions and 1 to completely thawed sediment or bedrock. The partially thawed part of the profile (water content between 0 and 1) extends deeper than the $0^{\circ} \mathrm{C}$ isotherm because ice starts to thaw at $-1^{\circ} \mathrm{C}$. Panels ( $\mathbf{d}$ and $\mathbf{e}$ ): as for (b) and (c) but with a sediment cover (yellow fill). Note that the effects of the latent heat are more pronounced because the sediment has higher porosity than bedrock. The latent heat dampens the propagation of temperature variations into the subsurface and the freeze-thaw events are shallow in the case of thick sediment cover.

reviews). Ice-segregation growth has been shown to operate primarily in the temperature interval from -8 to $-3{ }^{\circ} \mathrm{C}$ (Walder and Hallet, 1986; Anderson, 1998). Furthermore, in order for ice lenses to grow, water must be available and able to flow towards the ice lenses. This requires a continuous positive thermal gradient (increasing temperature) from the ice lenses to the water. Because the thermal gradient influences the flow rate of water, Hales and Roering (2007) suggested that frost-cracking intensity scales with the thermal gradient in situations where water is available along a path following the positive thermal gradient. Anderson et al. (2012) supplemented this approach with a penalty function that reduces frost-cracking efficiency dependent upon the distance that water must migrate through low-permeable frozen bedrock to reach the ice lenses. We continue this line of thought by scaling the frost-cracking intensity with the magnitude of the thermal gradient multiplied by the volume of water available to the ice-segregation growth process:
$\operatorname{FCI}(z, t)= \begin{cases}\left|\frac{\mathrm{d} T}{\mathrm{~d} z}\right| V_{\mathrm{w}}(z) & \text { if }-8^{\circ} \mathrm{C}<T<-3^{\circ} \mathrm{C} \\ 0 & \text { else } .\end{cases}$

Here $\operatorname{FCI}(z, t)$ is the cracking intensity at time $t$ and depth $z$ below the surface.

The water volume available for ice-segregation growth, $V_{\mathrm{w}}$, is calculated by integrating the occurrence of water along the path, $\ell$, that starts at depth $z$ and follows the positive thermal gradient:

$V_{\mathrm{w}}(z)=\int_{\ell} \phi\left(z^{\prime}\right) w_{\mathrm{f}}\left(z^{\prime}\right) e^{-\Gamma\left(z^{\prime}\right)} \mathrm{d} z^{\prime}$

Note that $\ell$ is either up or down along the vertical profile, depending on the sign of the thermal gradient. $\ell$ extends from depth $z$ to either (i) the surface, (ii) the profile bottom, or (iii) the point where the thermal gradient changes sign. Following Anderson et al. (2012), we apply a penalty function $e^{-\Gamma\left(z^{\prime}\right)}$ that depends on the distance the water must migrate to arrive at the point of ice segregation. This function depends on the properties of the material located between the water (at $z^{\prime}$ ) and the point of ice segregation $(z)$. We therefore compute $\Gamma\left(z^{\prime}\right)$ by integrating the flow resistance, $\gamma$, from $z$ to $z^{\prime}$ :

$\Gamma\left(z^{\prime}\right)=\int_{z}^{z^{\prime}} \gamma\left(z^{\prime \prime}\right) \mathrm{d} z^{\prime \prime}$.

Applying a constant value for $\gamma\left(2 \mathrm{~m}^{-1}\right)$ results in a penalty function identical to that used by Anderson et al. (2012). However, because ice segregation occurs at temperatures below $-3^{\circ} \mathrm{C}$ and water is available only for higher temperatures, water must always flow through a mixture of frozen or unfrozen bedrock or sediment. To characterise the range of permeabilities, we apply four different $\gamma$ values, representing (i) unfrozen sediment, (ii) frozen sediment, (iii) unfrozen bedrock, and (iv) frozen bedrock (Table 1). Note that $e^{-\Gamma\left(z^{\prime}\right)} \rightarrow 0$ for $z^{\prime} \rightarrow D$ ensures that the existence of the profile bottom does not limit the water volume available for the cracking process.

By incorporating a measure for the actual amount of water present in the pore spaces of bedrock and sediment, we capture an important effect of the frost-cracking process: that sediment overlying bedrock acts as a water reservoir. The porosity of sediments is significantly higher than for bedrock, and $V_{\mathrm{w}}$ therefore increases rapidly if an unfrozen sediment layer exists in proximity to frozen bedrock. Yet, we suggest that the positive effect of water availability only increases up to a critical water volume, $V_{\mathrm{w}}(z) \leq V_{\mathrm{cw}}$ (Table 1), which defines the situation when the frost-cracking process is no longer limited by the availability of water. In Sect. 4.3, we explore the sensitivity of the model to the assumptions made regarding water availability and discuss the implications for our results. 


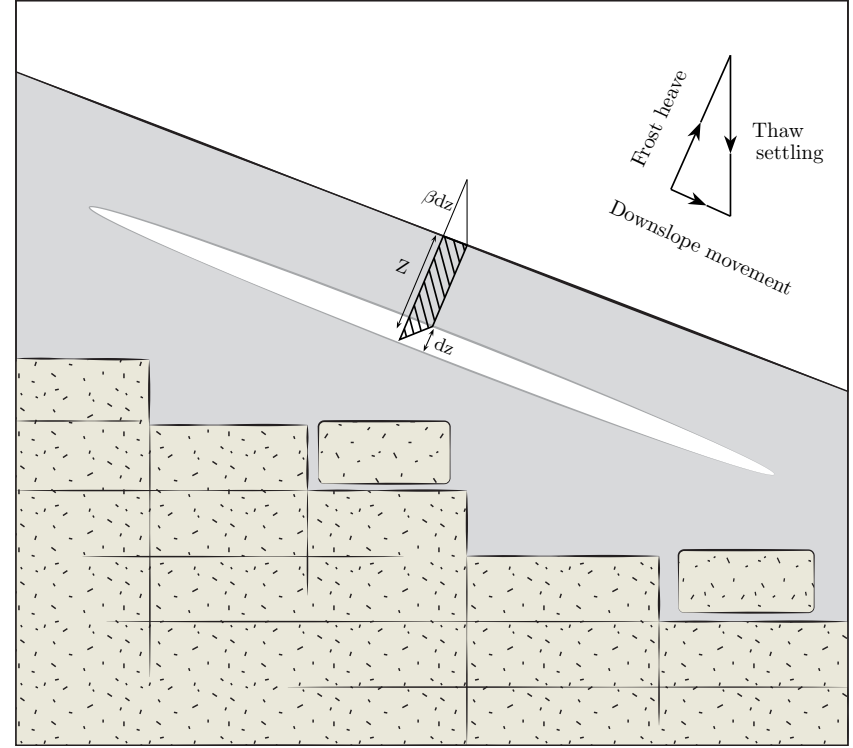

Figure 4. Sketch of the frost-creep mechanism. The downslope movement of sediment (grey) occurs due to the angle discrepancy between frost heave and thaw settling. The white area marks a zone of thickness, $\mathrm{d} z$, that expands and contracts (by $\beta \mathrm{d} z$ ). The downslope sediment flux caused by this freeze-thaw event is represented by the hatched area. Note that the expansion has been exaggerated for illustration purposes; in the model $\beta$ is 0.05 .

Finally, the annually averaged frost-cracking intensity, $\overline{\mathrm{FCI}}$, is computed by depth-integrating the cracking intensity and averaging this depth-integrated value throughout a year:

$\overline{\mathrm{FCI}}=\frac{1}{T_{\mathrm{a}}} \int_{0}^{T_{\mathrm{a}}} \int_{0}^{D} \mathrm{FCI}(z, t) \mathrm{d} z \mathrm{~d} t$,

where $T_{\mathrm{a}}$ is 1 year and $D=20 \mathrm{~m}$ is the thickness of the profile.

\subsection{Quantifying frost creep}

Frost heave results from the expansion of fine-grained sediment when subjected to freezing and associated ice-lens growth (e.g. Chamberlain, 1981; Harris et al., 1993). The expansion due to freezing is perpendicular to the slope of the surface while the thaw-conditioned contraction is vertical owing to gravity. The surface-parallel displacement of sediment arises from this angle discrepancy between directions of expansion and contraction (Fig. 4) (Anderson, 2002), a process noted long ago (Davison, 1889).

The contribution to horizontal sediment transport is

$$
Q=-N_{\mathrm{f}} \beta z \mathrm{~d} z \nabla h,
$$

where a sediment layer of thickness $\mathrm{d} z$ located at depth $z$ experiences a number of freeze-thaw events, $N_{\mathrm{f}}$. Here $\nabla h=$ $\left[\frac{\partial h}{\partial x}, \frac{\partial h}{\partial y}\right]$ is the bed topographic gradient and $\beta$ is the relative expansion of the layer when frozen (Fig. 4). The unit of $\boldsymbol{Q}$ is square metres as it records the volume of sediments advected per unit width of the hillslope. We note that the dependency on $z$ arises from the fact that expansion of a buried sediment layer causes passive transport of all sediments above this layer.

We compute the number of freeze-thaw events in terms of the water fraction:

$N_{\mathrm{f}}=\frac{1}{2} \int_{t}\left|\frac{\partial w_{\mathrm{f}}}{\partial t}\right| \mathrm{d} t$.

$N_{\mathrm{f}}=1$ if the integral covers the full period of a single frostheave event because a full frost-heave cycle involves shifting the water fraction from 1 to 0 and back to 1 again. This formulation of $N_{\mathrm{f}}$ also captures the effect of partial frost-heave events, which may be important for the frost-creep rate if the MAT is close to the freezing point. Note that $\frac{\partial w_{\mathrm{f}}}{\partial t}$ is governed by the transient heat equation as demonstrated in Sect. 3.1 (Eq. 13) and is therefore rate-limited by thermal diffusion and the exchange of latent heat.

Integrating contributions from all sediment elements along the vertical profile and averaging the total frost-heave activity per year, yields the following annually averaged sediment flux $\left(\mathrm{m}^{2} \mathrm{a}^{-1}\right)$ :

$\boldsymbol{q}=-\left[\frac{\beta}{2 T_{\mathrm{a}}} \int_{0}^{T_{\mathrm{a}}} \int_{0}^{S}\left|\frac{\partial w_{\mathrm{f}}}{\partial t}\right| z \mathrm{~d} z \mathrm{~d} t\right] \nabla h$.

We can now formulate the sediment frost-creep process as a standard hillslope transport law:

$\frac{\partial S}{\partial t}=-\nabla \cdot \boldsymbol{q}$,

where

$\boldsymbol{q}=-\kappa \nabla h$

and

$\kappa=-\frac{\beta}{2 T_{\mathrm{a}}} \int_{0}^{T_{\mathrm{a}}} \int_{0}^{S}\left|\frac{\partial w_{\mathrm{f}}}{\partial t}\right| z \mathrm{~d} z \mathrm{~d} t$

is the transport efficiency $\left(\mathrm{m}^{2} \mathrm{a}^{-1}\right)$, and $S$ is the local sediment thickness.

This formulation for the transport efficiency (Eq. 23) fulfils the basic requirement that sediment discharge approaches 0 where there is no sediment to transport. Note also that $\kappa$ is limited by sediment thickness until the thickness exceeds the annual penetration depth of the phase-change window ( -1 to $\left.0^{\circ} \mathrm{C}\right)$.

The parameter $\beta$ depends on the sediment grain-size distribution, as this influences the susceptibility to frost heave. Silty 


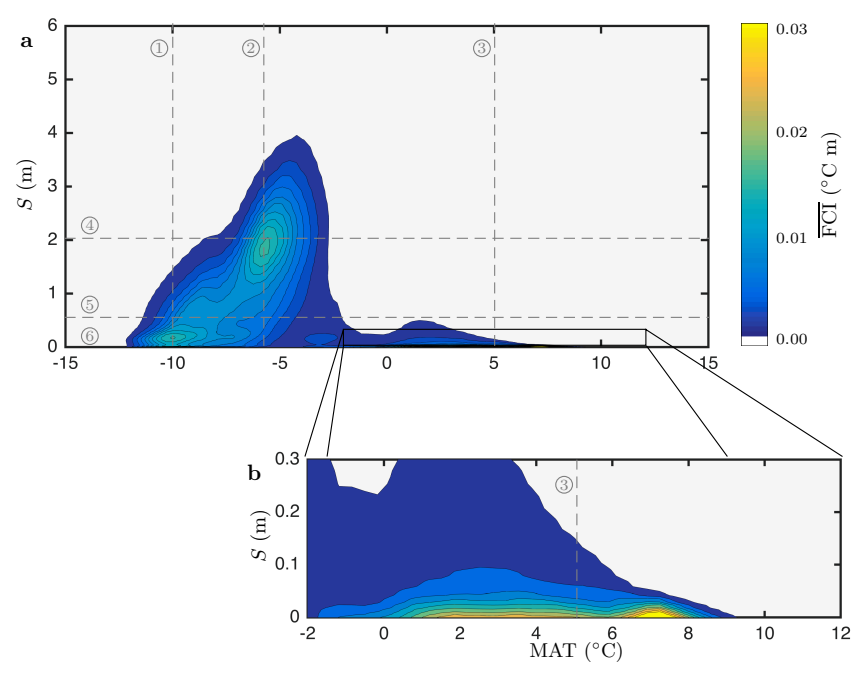

Figure 5. The integrated frost-cracking intensity, $\overline{\mathrm{FCI}}$, as a function of mean annual temperature, MAT, and sediment thickness, $S$. Each point in the contour plot corresponds to the annually integrated $\overline{\mathrm{FCI}}$ for a particular combination of MAT and $S$. The contour plot was constructed from 8100 such combinations. The porosity of both sediment and bedrock is assumed to be $100 \%$ saturated by water. The dashed lines with numbers correspond to transects that are shown in Fig. 6. The inset shows the $\overline{\mathrm{FCI}}$ for positive MATs in detail. Here $\overline{\mathrm{FCI}}$ is strongly limited by sediment thickness and decays rapidly when $S$ increases to more than a few centimetres.

sediments are the most frost susceptible (high $\beta$ ) (Chamberlain, 1981; Harris et al., 1993), while coarser sediments are likely associated with smaller values for $\beta$. We do not vary $\beta$ in this study ( $\beta=0.05$, adopted from Anderson (2002)). However, we note here that the influence of $\beta$ is to linearly scale the transport efficiency $(\kappa)$, and variation in frost susceptibility therefore has an highly predictable influence on rates of frost creep.

\section{Results}

\subsection{Rates of frost cracking}

The modelled FCI shows that frost cracking can occur under very diverse climatic conditions depending on sediment thickness and that the effect of sediment cover on frostcracking rate depends on climate (Figs. 5 and 6). The model results point to peaks in frost-cracking activity in three distinct environments.

Firstly, frost cracking can occur in a relatively warm climate (MAT $>0{ }^{\circ} \mathrm{C}$ ), where the temperature drops below $0{ }^{\circ} \mathrm{C}$ only during the coldest nights in winter (Fig. 5b). The rapid diurnal temperature variations result in cold conditions and a steep temperature gradient close to the surface. At the same time, positive temperatures, and hence water, exist at only $20-30 \mathrm{~cm}$ depth below the surface (Fig. 7a). Since there is no water present at the surface, the water necessary for frost
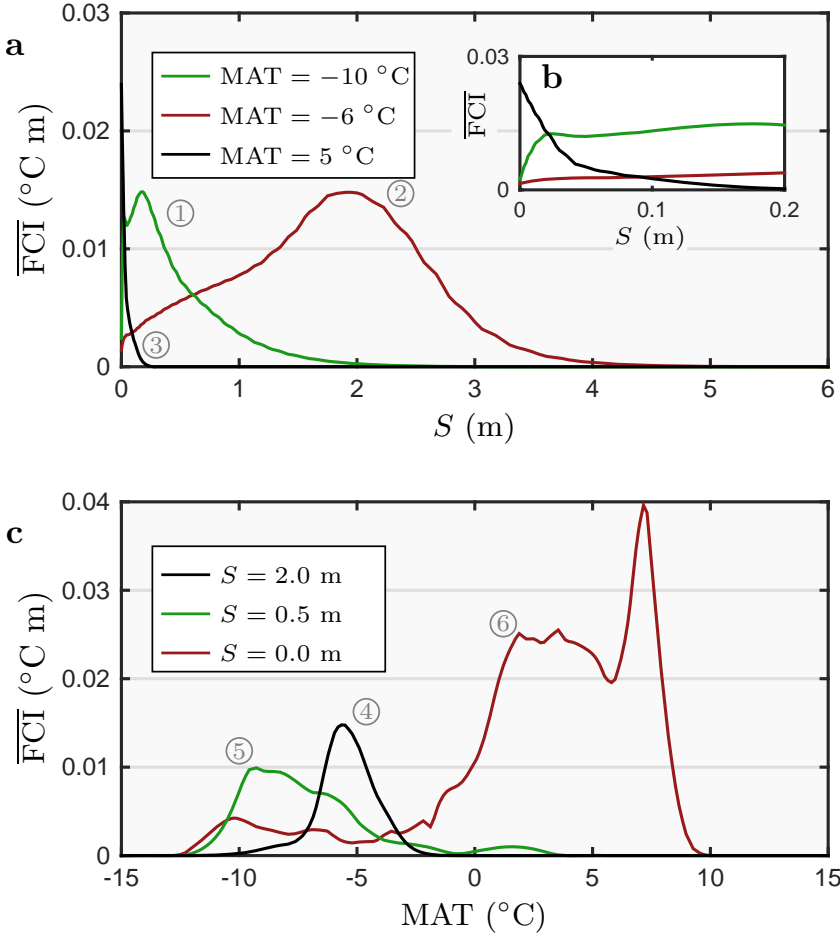

Figure 6. The integrated frost-cracking intensity along profiles shown in Fig. 5. Panel (a): profiles along the $S$ axis illustrate how $\overline{\mathrm{FCI}}$ depends on sediment thickness for three different MATs. Note the exponential decay function for MAT $=5^{\circ} \mathrm{C}$ and the humped function for the two colder settings. Panel (b): inset highlighting the change in $\overline{\mathrm{FCI}}$ for thin sediment cover. Panel (c): profiles of $\overline{\mathrm{FCI}}$ parallel to the MAT axis showing how the effects of climate depend on sediment thickness. Areas with no or very little sediment cover (red line) have the highest $\overline{\mathrm{FCI}}$ in warm regions, where rapid freezing events in winter promote intense cracking. In regions with permafrost (MAT $<0{ }^{\circ} \mathrm{C}$ ), frost cracking is most intense under thicker sediments.

cracking must come from within the bedrock and the resulting frost-cracking intensity thus depends critically on the water migration capacity of the bedrock (parameters $\gamma_{\mathrm{bc}}$ and $\gamma_{b w}$ in Table 1). As the freezing front does not penetrate far into the ground, the FCI is dampened by any sediment, which prevents the bedrock from reaching temperatures in the frost-cracking window. This effect is further enhanced by the higher water content of the sediment that stalls the freezing front because of latent heat. Frost cracking in this environment can therefore occur only where the sediment cover is very thin $(\leq 20 \mathrm{~cm})$ or absent (Fig. $5 \mathrm{~b}$ and line 3 in Fig. 6a).

Secondly, frost cracking is promoted in an environment where the deep subsurface is frozen $\left(\mathrm{MAT}<0^{\circ} \mathrm{C}\right.$ ), but where surface temperatures rise above the melting point during summer and on warm days in spring and autumn (Figs. 5 and $7 \mathrm{~b}$ ). The water driving frost cracking in this setting comes from the surface because the deeper ground is permanently frozen and because the annual temperature oscilla- 

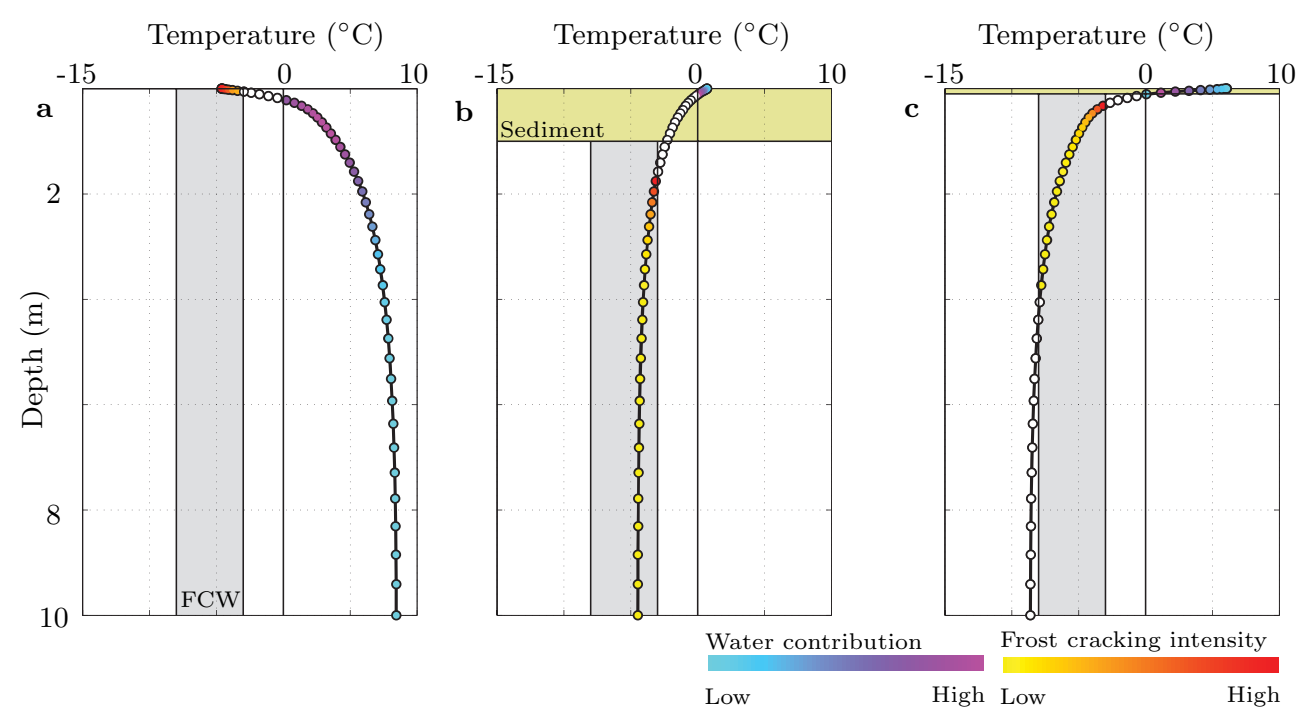

Figure 7. Three examples of temperature profiles under different field scenarios. The circles mark the position of finite-element nodes: blue-violet colours indicate zones that contribute water; red-yellow colours indicate zones with active frost cracking. The grey temperature interval marks the frost-cracking window (FCW). Panel (a): a warm, bare-bedrock setting with MAT $=8^{\circ} \mathrm{C}$ and therefore no permafrost. Frost cracking occurs very close to the surface when temperatures drop into the FCW in winter. Panel (b): a colder situation with permafrost and MAT within the FCW (MAT $=-4.5^{\circ} \mathrm{C}$ ). Frost cracking takes place a few metres below the surface at the bottom of the active layer. By providing water the sediment cover (yellow fill) promotes frost cracking until the sediment thickness exceeds the active-layer thickness. Panel (c): a situation with extensive permafrost and MAT below the FCW (MAT $=-8.5^{\circ} \mathrm{C}$ ). Frost cracking is now most active close to the surface in summer. Again, because water must come from above the FCW, a thin sediment layer amplifies frost cracking. The white circles are nodes that are outside the FCW and that do not contribute water.

tion ensures a negative thermal gradient (temperatures decrease with depth) during summer periods, driving water downwards from the surface. Because the water comes from above, the presence of a sediment layer may accelerate cracking due to its water-holding capacity. On the other hand, the relatively large penetration depth $(\sim 2 \mathrm{~m})$ of the annual temperature oscillation results in a rather gentle temperature gradient, and the distance between the positive temperatures at the surface and the bedrock within the FCW is a few metres (Fig. 7b). The most efficient frost cracking therefore takes place at the sediment-bedrock interface. Optimal conditions for frost cracking occur where the lower limit of the sediment coincides with the depth to the FCW, and this causes the FCI in cold environments to peak under a sediment cover $1-2 \mathrm{~m}$ thick.

Thirdly, frost cracking also occurs in very cold climates (MAT $\leq-8^{\circ} \mathrm{C}$ ), where only the warmest days in summer experience surface temperatures above $0^{\circ} \mathrm{C}$. This is reflected in the tail of the FCI distribution towards relatively thin sediment covers for very cold temperatures (Fig. 5a). The low temperatures limit the amounts of water generated at the surface, and the transport of water is restricted through the frozen sediment and bedrock below. Frost cracking thus occurs only due to the large but shallow thermal gradient generated by the diurnal temperature variation (Fig. 7c). As a result, sediment thickness is critical: a thin sediment layer $(\leq 10-20 \mathrm{~cm})$ promotes cracking owing to its water content, whereas thicker sediment $(\geq 20 \mathrm{~cm}$ ) limits cracking because the transport path of water down to the top of the bedrock becomes too long. The colder the environment is, the shallower the sediment cover must be to accommodate frost cracking at the top of the bedrock.

Frost cracking in our model is very limited for MATs just below $0{ }^{\circ} \mathrm{C}$, an outcome common to previous models (Hales and Roering, 2009; Anderson et al., 2012). This result may seem counter-intuitive, but at just below $0{ }^{\circ} \mathrm{C}$ MAT the mean annual ground temperature is higher than the FCW. Temperatures required for frost cracking are therefore restricted to near-surface zones in winter; a time when the deeper subsurface is frozen and there is no water available. Conversely, when water does become available in summer, subsurface temperatures are too warm for frost cracking. Hence, frostcracking activity is suppressed although temperatures oscillate around $0^{\circ} \mathrm{C}$. The temperature variation does, however, lead to efficient sediment transport by frost creep as demonstrated in the next section. The model results thus point to an offset between the MATs that promote efficient frost cracking and those that promote transport by frost creep.

\subsection{Rates of frost creep}

The modelled frost-transport efficiency (Fig. 8) shows the combined result of frequent, but shallow, mass movement caused by the diurnal temperature variations and the larger, 

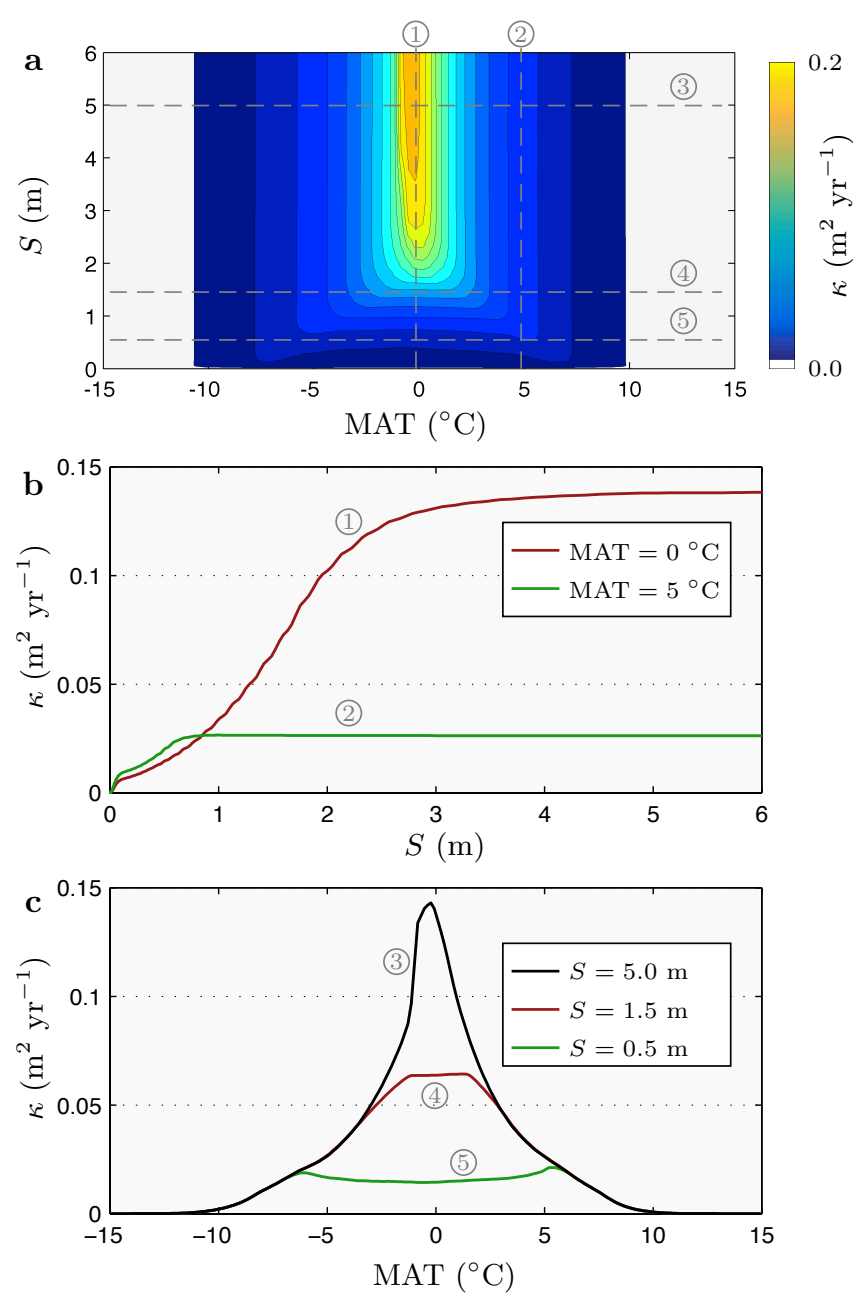

Figure 8. Panel (a): contours of the integrated frost-creep efficiency, $\kappa$, as a function of MAT and sediment thickness, $S$. Locations of transects plotted in (b) and (c) are shown with grey, dashed lines and numbers.

but less frequent, movement caused by the deep penetration of the annual temperature oscillation. The contribution of the diurnal oscillations is minor and the overall pattern is largely controlled by two properties related to the annual temperature oscillation.

Firstly, the maximum penetration depth of the freezing and thawing front depends on how close the MAT is to the phasechange interval $\left(-1\right.$ to $\left.0^{\circ} \mathrm{C}\right)$. For thermal profiles with MATs close to the phase-change interval, the front penetrates to greater depths in the subsurface. Because sediment is passively transported on top of the thawing layer, a deep-seated phase-change event leads to greater mass movement than a shallower phase-change event. This effect is most clearly seen at sediment thicknesses above a few metres (Fig. 8). For a constant sediment thickness, the transport decreases with increasing difference between MAT and the phase-change interval (Fig. 8c).
Secondly, the maximum transport rate for any particular MAT (along lines parallel to the $S$ axis in Fig. 8) occurs when the sediment thickness corresponds to the maximum penetration depth of the freezing and thawing front. At sediment thicknesses less than optimal thickness, freezing or thawing continues into the underlying bedrock, which does not increase the transport. The transport efficiency in this interval is limited by the sediment thickness and thus increases until the optimum thickness is reached (Fig. 8b). For sediment thicknesses exceeding optimal thickness, the frost-transport efficiency is limited by the penetration depth of the freezing and thawing front and a plateau is attained with no further increase in transport efficiency. The optimal sediment thickness is highest for MATs close to the phase-change interval where the annual temperature variation causes the deepest penetration of the freezing and thawing front.

The diurnal temperature oscillations extend the MAT interval for which transport occurs to more extreme temperature values. For these extreme temperatures, transport occurs in shallow sediment packages only because the surface temperatures on warm summer days or cold winter nights support freezing or thawing.

\subsection{Model sensitivity}

The modelled rates of frost cracking and frost creep reflect the basic assumptions and chosen parameters in the model. A different set of parameters may lead to different results. In this section, we hence explore and discuss the sensitivity of the model results to variations in the most important parameters and assumptions.

\subsubsection{Thermal properties}

The frost-cracking intensity and the efficiency of frost-driven sediment transport are both highly dependent on the modelled temperature profiles. The parametrisation of the thermal model therefore has a significant influence on the predicted rates of sediment transport and bedrock weathering.

While variations in thermal conductivity and volumetric heat capacity have only a minor influence on the rates of frost cracking and frost creep, the amplitude of the annual temperature oscillation, $\mathrm{d} T_{\mathrm{a}}$, has a significant impact. $\mathrm{d} T_{\mathrm{a}}$ is highly variable in natural environments and varies over time due to changes in climate. In general, $\mathrm{d} T_{\mathrm{a}}$ increases with distance from the coast and from the equator (Legates and Willmott, 1990). Increasing $d T_{\mathrm{a}}$ in the model leads to higher values of both FCI and sediment transport efficiency, $\kappa$ (Fig. 9). It also leads to frost cracking and transport in a wider range of MATs, as well as to frost cracking for thicker sediment cover. For example, the $\mathrm{FCI}$ for MAT $=-10^{\circ} \mathrm{C}$ increases almost 2 orders of magnitude when $\mathrm{d} T_{\mathrm{a}}$ is raised from 6 to $12^{\circ} \mathrm{C}$. It is therefore important to incorporate knowledge of $\mathrm{d} T_{\mathrm{a}}$ when estimating frost-cracking rates in areas of unusually high or low annual temperature variations. 

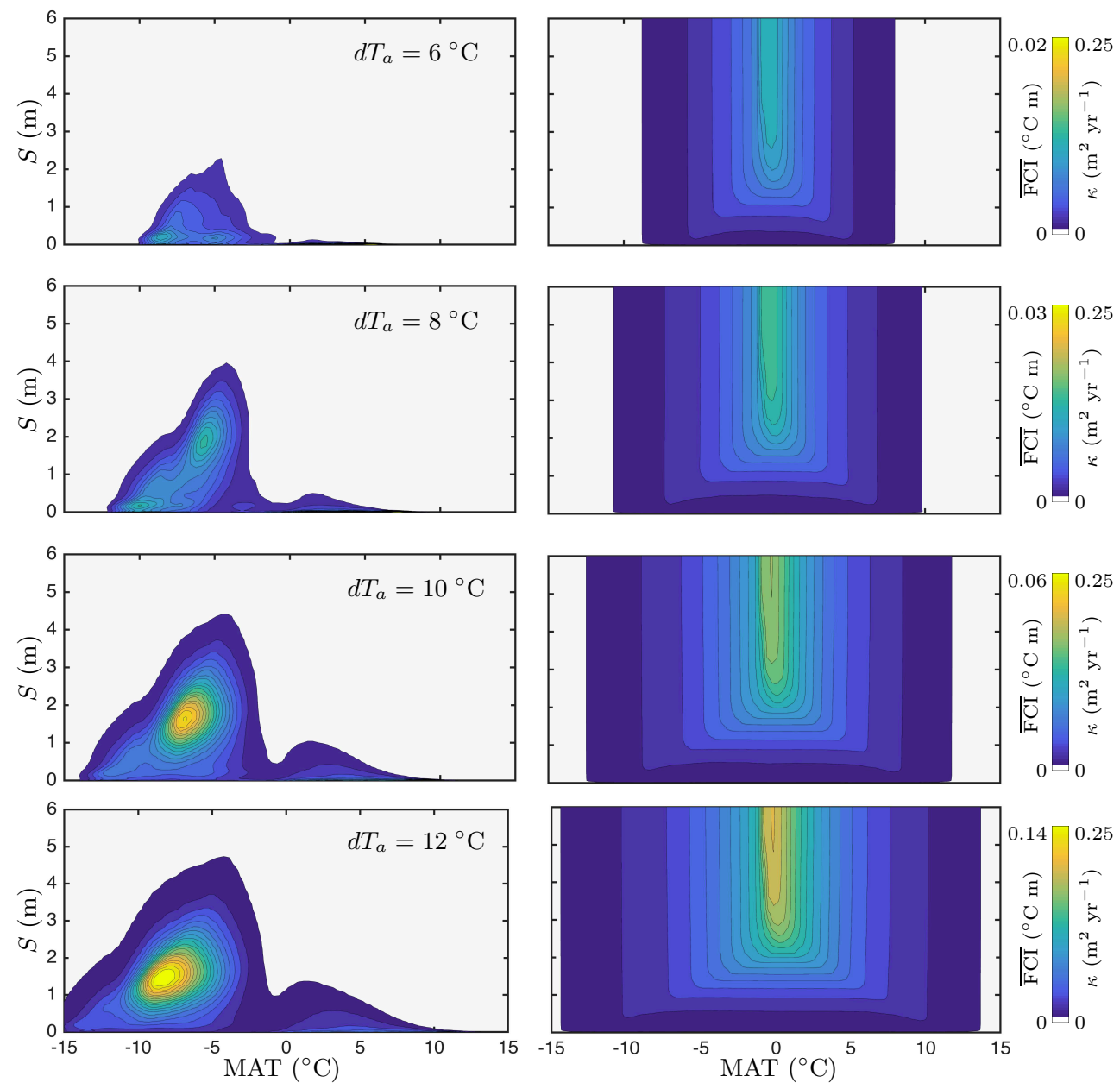

Figure 9. The effect of the amplitude of the annual temperature variation, $\mathrm{d} T_{\mathrm{a}}$, on frost cracking (left) and frost creep (right). Note that the colour scale for $\overline{\mathrm{FCI}}$ varies between situations with different $\mathrm{d} T_{\mathrm{a}}$.

\subsubsection{Effect of a snow cover}

We simulate the effect of snow cover by reducing the amplitude of the diurnal temperature oscillations in winter (Fig. 10a). The motivation for this approach is that thick snow insulates the ground below and dampens the downward propagation of rapid variations in air temperature. This representation of snow cover does not fully capture the complex interactions between snow and ground temperatures that occur in natural systems (see, e.g., Bartlett et al., 2004). However, the aim here is to illustrate first-order effects on the rates of both frost cracking and sediment transport.

Because the frost-cracking intensity in positive MAT environments depends on cold temperatures at night in winter, the FCI is lowered substantially when diurnal variations are dampened. With a snow cover present, efficient frost cracking occurs only for cold temperatures (MAT $<-5^{\circ} \mathrm{C}$ ) under sediment covers up to $3 \mathrm{~m}$ thick (Fig. 10b). The frost-creep efficiency $(\kappa)$ is less affected, but for high, positive MATs $\left(>5^{\circ} \mathrm{C}\right)$ sediment transport is reduced when the diurnal win- ter oscillations are dampened by snow cover. Diurnal temperature variations that cause short-lived freezing events during winter nights drive the sediment transport for high MATs. Even without snow cover, the induced transport is modest because the frost propagates only a few centimetres into the ground, but with snow cover present the transport mechanism becomes negligible for positive MATs.

\subsubsection{Water availability}

Water is essential for driving frost cracking at sub-zero temperatures, but the implementation of the water dependency differs among existing models. In the following, we briefly review the different approaches and discuss the sensitivity of our results to how water availability is quantified.

To account for the influence of water on frost-cracking rates, Hales and Roering $(2007,2009)$ included the condition that positive temperatures should be present somewhere in the temperature profile for frost cracking to take place. They also scaled the FCI with the temperature gradient, which is 

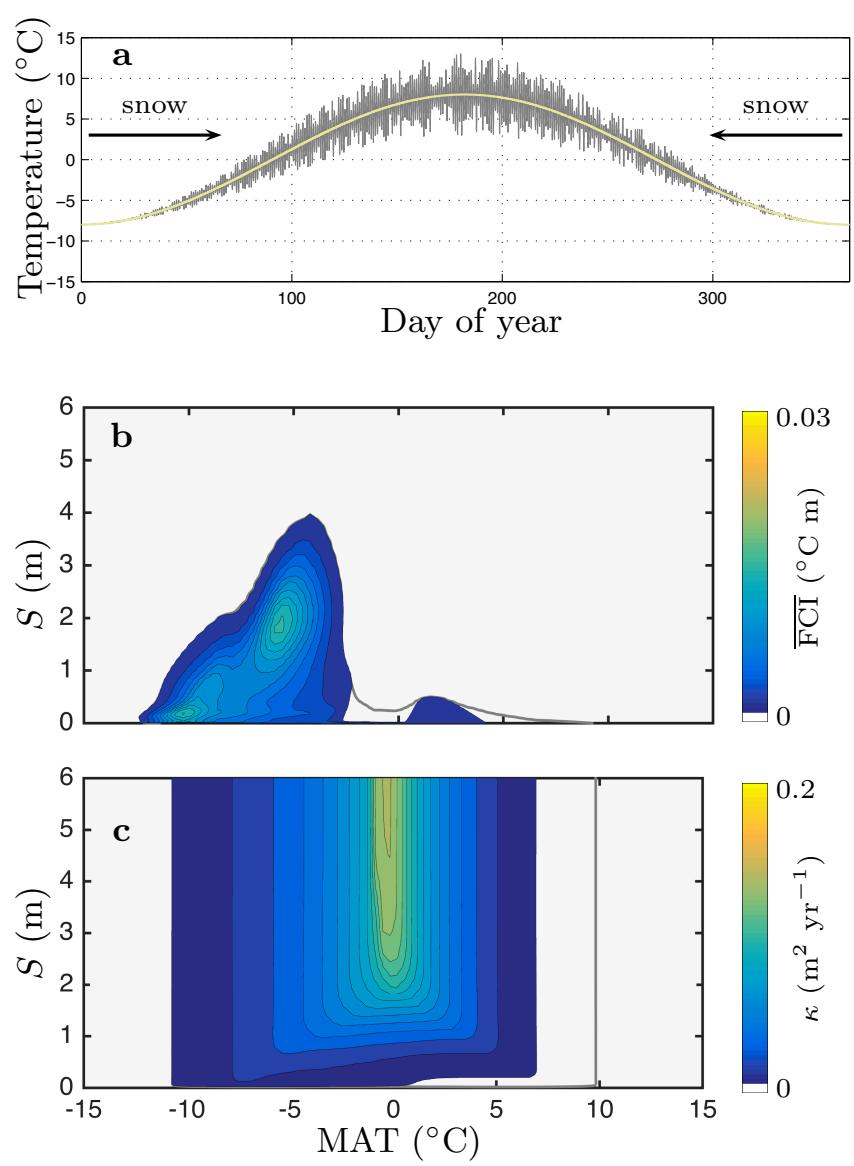

Figure 10. Panel (a): the amplitude of the diurnal temperature variations at the surface is dampened, simulating an insulating snow cover on the ground during winter (indicated by arrows). Panel (b): the snow cover limits the integrated frost cracking for MATs around and above $0{ }^{\circ} \mathrm{C}$. The lowest contour level of Fig. 5 is indicated with a black line for easy comparison. Panel (c): the snow cover reduces the frost-creep efficiency at positive MATs because the sediment is insulated from the cold air temperatures on cold nights in winter. Again, the black line represents the lowest contour level of Fig. 8.

thought to determine the flow rate of water. Anderson et al. (2012, p. 306) argued that the growth rate of cracks should be limited not only by the flow rate but also by "the distance water must be moved through cold materials to get to the site of potential frost cracking". Based on this idea, they introduced a penalty function that makes the FCI decay exponentially over the distance between the zone of frost cracking and positive temperatures. This implementation is in accordance with experimental results, which indicate that "an external moisture source close to a freezing rock contributes to ice segregation" (Matsuoka, 2001, p. 304). In line with these results, we suggest that FCI should scale with not only migration distance but also the amount of accessible water in the profile. Furthermore, we suggest that water should be limited to a greater degree when it flows through cold bedrock than when it flows through warm sediment, corresponding to differences in the permeability of these materials. We have therefore integrated the available water and included varying flow restrictions based on the thermal state and porosity of the material. Yet, since the true water dependency is poorly constrained and since the flow restriction parameters are chosen based on an entirely qualitative estimate, we document the influence of our parametrisation by exploring the FCI patterns that arise from a range of alternative choices (Fig. 11). The sensitivity of the model to variations alone in the flow restriction parameters is shown in a supplementary figure. Overall, an increase in bedrock flow restriction parameters leads to reduced frost cracking at positive MATs, whereas an increased penalty for negative temperatures shifts the maximum FCI towards thinner sediment. Below, we focus on how variations in the fundamental assumption influence the general pattern of FCI when compared to our standard model (Fig. 11a).

In the first case, the flow restriction of water is constant $\left(2 \mathrm{~m}^{-1}\right)$ and hence independent of the porosity or thermal state of the subsurface (Fig. 11b). Compared to the standard model (Fig. 11a), this leads to a shift in the peak at negative MAT towards smaller sediment thicknesses; an effect of more restricted water flow in warm sediment, which diminishes the contribution of porous water-filled sediment close to the frost-cracking zone. On the other hand, the less restricted flow in cold bedrock leads to increased frost cracking in zones with MAT $\geq 0^{\circ} \mathrm{C}$ and $S \leq 1 \mathrm{~m}$. The consequence of less restrictive flow in bedrock suggests that crack propagation in bedrock with a high fracture density can be very efficient, leading to a positive feedback between the degree of rock damage and frost-cracking susceptibility.

In the second case (Fig. 11c), which resembles the model by Anderson et al. (2012), FCI still depends on the distance from bedrock in the FCW to the closest water, whereas the amount of water available now has no effect. The flow restriction of water is again constant $\left(2 \mathrm{~m}^{-1}\right)$ and independent of the porosity or thermal state. Compared to our standard model, FCI is now reduced for negative MAT and thick sediment. The humped relationship between frost cracking and sediment thickness essentially disappears because frost-cracking is not accelerated by water supplied from the porous sediment layer.

In the third case, following Hales and Roering (2007), frost cracking is allowed to take place whenever water is present along a continuous thermal gradient (Fig. 11d); there is no dependency on migration distance or amount of water. Like in Fig. 11c, the lack of sensitivity to water volume removes the humped FCI-sediment relation for negative MATs. This implementation furthermore gives rise to a very sharp jump in $\mathrm{FCI}$ at $0^{\circ} \mathrm{C}$, as is also seen in the original model by Hales and Roering (2007). Frost cracking increases around $0^{\circ} \mathrm{C}$ MAT because water becomes available at great depth where the temperature reflects the MAT. The increase is sudden because frost cracking is not restricted by the great distance between cold bedrock and water (where $T \geq 0{ }^{\circ} \mathrm{C}$ ). 

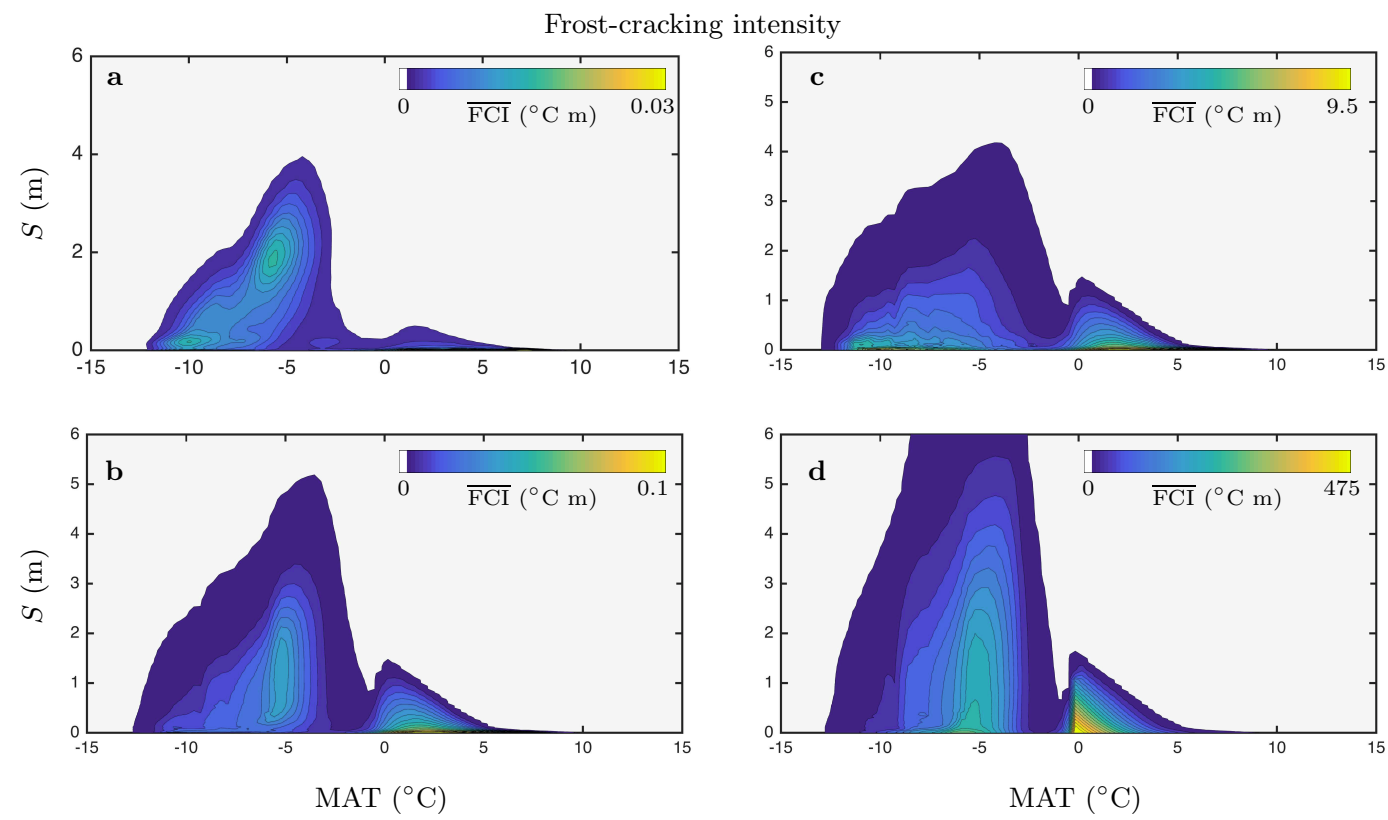

Figure 11. The integrated frost-cracking intensity as a function of sediment thickness and MAT, for varying water-penalty implementations. Panel (a): our standard model (same as Fig. 5). Panel (b): the distance to the water source and the amount of water available influences the penalty function, but in contrast to our standard model, the flow restriction parameters, $\gamma$, are constant $\left(2 \mathrm{~m}^{-1}\right)$ and independent of the porosity or thermal state. Panel (c): flow restriction parameters are constant $\left(2 \mathrm{~m}^{-1}\right)$, and the distance between an element in the FCW and the nearest water source scales the FCI. Compared to our standard model, the FCI is unaffected by the amount of water available at the source (the porosity is not accounted for). This model implementation is similar to that of Anderson et al. (2012). Panel (d): frost cracking occurs whenever water is present along the vertical profile in the direction of warming temperature, independent of the distance to, or amount of water available at, the source. This model implementation is similar to the model by Hales and Roering (2007).

Frost-cracking intensity in our model scales with the volume of water available (Eq. 14), but only up to a fixed limit, $V_{\mathrm{cw}}$ (Table 1). We chose this implementation because we believe that water availability can limit frost cracking only up to a certain threshold. Although the value for $V_{\mathrm{cw}}(0.04 \mathrm{~m})$ is not supported by empirical data, our experiments reveal that rates of frost cracking and sediment transport are rather insensitive to variations in $V_{\mathrm{cw}}$. Only when $V_{\mathrm{cw}}$ is significantly reduced does it affect the computed FCI values, first as a reduction in FCI for positive MATs $\left(V_{\mathrm{cw}}=0.005 \mathrm{~m}\right)$ and then by also lowering frost cracking for negative MATs $\left(V_{\mathrm{cw}}=0.001 \mathrm{~m}\right)$.

To summarise: the choice of flow restriction parameters influences the conditions for which FCI is predicted to be highest, but the general humped relationship between FCI and sediment thickness is preserved for negative MATs (Fig. 11a, b). On the other hand, the humped relationship disappears if the amount of water is not a rate-limiting factor as we assume in our standard model. This means that FCI peaks with little or no sediment cover for both negative and positive MATs (Fig. 11c, d).

As this analysis has demonstrated, water availability is clearly an important issue for the predictive power of any frost-cracking model. We therefore return to this topic in the discussion (Sect. 5.4), and we follow up on effects for longterm periglacial landscape evolution in the companion paper (Egholm et al., 2015).

\subsubsection{Temperature thresholds for frost cracking}

Finally, we explore the influence of the FCW. Matsuoka (2001) summarises experiments and reports frost cracking between -5 and $0^{\circ} \mathrm{C}$ for high-porosity rocks (tuff, shale, chalk) and between -6 and $-3{ }^{\circ} \mathrm{C}$ for medium-porosity rocks (limestone, sandstones). The model by Walder and Hallet (1985) predicted frost cracking between -15 and $-4{ }^{\circ} \mathrm{C}$ for a marble and a granite. Thus, theory and experiments indicate that the thresholds for frost cracking are more gradual and lithology-dependent than what is captured by a general FCW from -8 to $-3{ }^{\circ} \mathrm{C}$. To explore the consequence of varying the FCW, we applied a range of FCW thresholds (some are shown in Fig. 12) and found that the lower boundary of the FCW does not affect the frost-cracking pattern appreciably unless the total width of the window becomes very narrow $\left(<1^{\circ} \mathrm{C}\right)$. It also shows (predictably) that raising the upper threshold for frost cracking leads to frost cracking at higher MAT. 

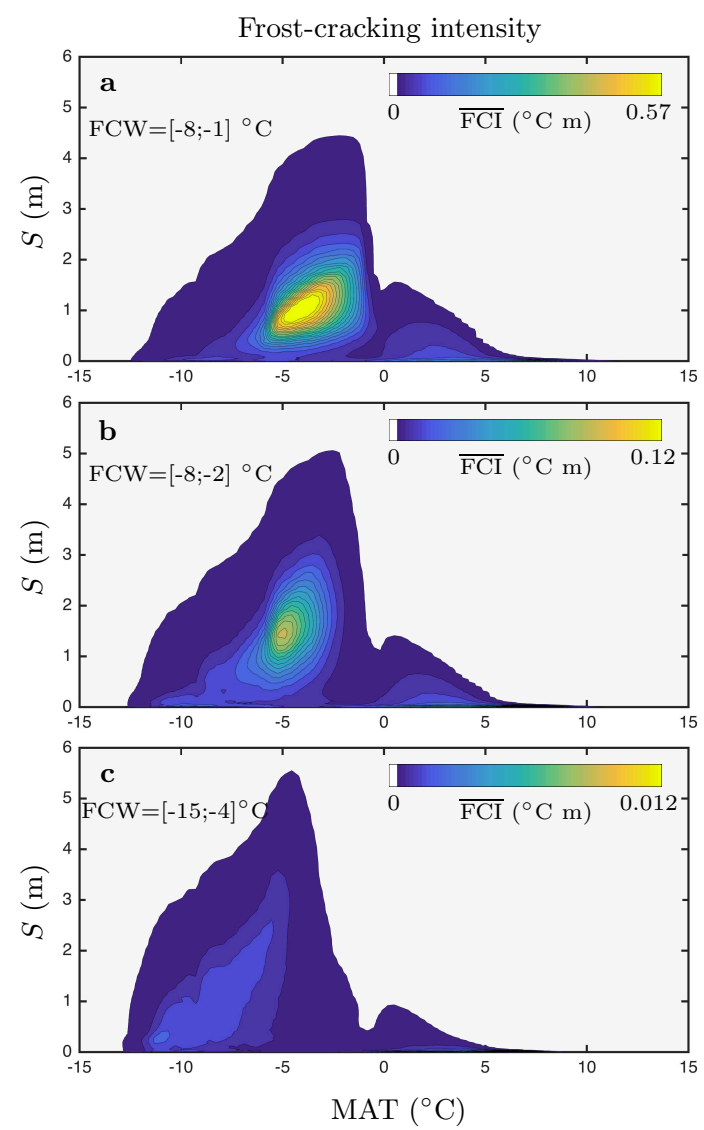

Figure 12. Integrated frost-cracking intensity as a function of sediment thickness and MAT, for frost-cracking windows of (a) $[-8 ;-1]$, (b) $[-8 ;-2]$, and (c) $[-15 ;-4]^{\circ} \mathrm{C}$. Note the different colour scales.

\section{Discussion}

\subsection{The rates of frost cracking}

The inclusion of the effects of variable sediment thickness in numerical models of frost cracking generates new insights into how climate and sediment cover combine to control bedrock weathering rates. First, when studying the modelled values for FCI along the MAT dimension (Fig. 6c), it is possible to compare our results to those of previous models. In the following, we thus compare the FCI results presented in this paper with the model introduced by Hales and Roering (2007, 2009) and that by Anderson et al. (2012).

While the Hales and Roering (2009) model includes two distinct zones of efficient frost cracking, one for negative MATs and one for positive MATs, Anderson et al. (2012) suggested that only the cold-region cracking could survive penalties to water transport in cold bedrock. Our model generally confirms the findings of Anderson et al. (2012), although we suggest that frost cracking can still be active in moderately warm climates, provided that the sediment cover is sufficiently thin $(<10 \mathrm{~cm})$ and the surface temperature is occasionally lowered into the FCW (Fig. 6c). Our model thus corroborates results suggesting the most intense scree production from bare bedrock at positive MATs (Hales and Roering, 2005). Frost cracking under warm conditions is, however, very sensitive to bedrock water saturation because water must come from within the bedrock when the surface is frozen in winter. Frost cracking in warm regions is also potentially limited by snow covers that insulates the bedrock from the cold atmosphere in winter (Fig. 10). Given that hillslope angle governs the likelihood of retaining snow cover as well as a sediment layer, our model indicates that frost cracking in warm regions mainly occurs in winter along steep and wet bedrock surfaces, such as valley sides and headwalls.

It is worth noting, however, that strong variations in bedrock strength may potentially surpass the effects of water availability, as the rate of ice segregation growth is likely to also depend on the size and geometry of bedrock cracks (Matsuoka, 2001).

\subsection{Soil production function}

It is generally accepted that the conversion of bedrock to sediment is related to the thickness of the sediment mantle, and the production of new sediment eventually stalls with increasing accumulation (Heimsath et al., 1997). However, the exact nature of this relation (soil production function) has been debated (see Humphreys and Wilkinson, 2007, for a review). Some have argued for an exponential decline in sediment production rate with thickening sediment cover (Dietrich et al., 1995; Heimsath et al., 1997), while others favour a relation in which soil production rate peaks (the "humped" function) under a finite sediment thickness (Gilbert, 1877; Carson and Kirkby, 1972; Wilkinson et al., 2005). The strongest argument for the latter model is that a thin sediment layer is more likely to retain moisture, which is a vital ingredient for physical and chemical weathering, whereas bare bedrock promotes run-off and remains dry much of the time.

Anderson (2002) argued for a humped soil production model to explain the presence of tors (bedrock knobs) at hill crests in the Laramide ranges of the western USA - an area experiencing pronounced frost action. According to Anderson (2002), the tors protrude because (1) divergent sediment transport away from the crests leaves the summits bare and (2) sediment production from bare bedrock is slower than sediment production in the surrounding soil-mantled slopes.

Assuming that sediment production scales with frostcracking intensity, our results suggest that the shape of the soil production function depends on temperature (Fig. 6). For positive MATs, sediment production decays exponentially with thickening sediment cover (line 3 in Fig. 6a). We note that this result relies on the assumption that moisture is present at all times. A variable moisture content in the outer 
decimetres of bare bedrock, e.g. due to seasonal variations as suggested by Sass (2005), could potentially limit frost cracking on bare bedrock during dry periods. The present model does not include such effects, since it assumes saturated conditions at all times. For negative MATs, sediment production first increases with sediment thickness (up to 1-2 m) and then decays exponentially with further sediment mantle thickening (lines 1 and 2 in Fig. 6a). The optimal sediment thickness (for which sediment production is maximised) decreases with decreasing MAT. Our model thus suggests that both the exponential decline and the humped soil production functions may be viable in the periglacial environment. Moreover, long-term temperature fluctuations are likely to result in switching between the two.

\subsection{Frost creep and depth-dependent transport}

High-frequency diurnal temperature variations represent the main driver of frost creep for thin sediment covers. The diurnal temperature variations do not penetrate far into the sediment and the freeze-thaw events that they cause are shallow and frequent. For sediment covers less than $1 \mathrm{~m}$ thick, the most efficient transport (highest $\kappa$ ) occurs for MATs around -6 and $+6{ }^{\circ} \mathrm{C}$ (Fig. $8 \mathrm{a}$ and c) because diurnal variations generate the highest number of freeze-thaw events for these thermal settings (Anderson et al., 2012). However, the annual temperature variation is more dominant for thicker mantles $(>1 \mathrm{~m}$ ), and its influence on creep is maximised for MATs around $0{ }^{\circ} \mathrm{C}$ (Fig. 8a and b). This is because the seasonal temperature variation is slow enough to penetrate much deeper into the sediment. Freeze-thaw in a deep sediment layer contributes far more to the sediment flux than shallow events because the overlying pile of sediment is passively transported when the deep layer expands and contracts.

The efficiency of sediment transport by frost creep $(\kappa)$ furthermore depends on sediment thickness because the frequency of freeze-thaw events decreases with depth into the sediment (Fig. 8). Although sediment flux initially increases with sediment thickness for all MATs, it saturates at a temperature-dependent limiting thickness, beyond which it becomes constant, akin to linear hillslope diffusion models (Fig. 8b). This type of sediment-thickness-dependent function is in close agreement with the hypothesised transport function by Anderson (2002) although it depends on climate. For MATs around $0{ }^{\circ} \mathrm{C}$, the annual temperature variation causes freezing and thawing up to $3 \mathrm{~m}$ into the sediment, whereas the freeze-thaw penetration depth is more limited under warmer and colder conditions, respectively. We therefore emphasise that our frost-creep model supports a transport function rooted in sediment thickness (e.g. Braun et al., 2001; Heimsath et al., 2005; Johnstone and Hilley, 2015) up to a limit of $\sim 3 \mathrm{~m}$ for MAT $\sim 0{ }^{\circ} \mathrm{C}$ and $<1 \mathrm{~m}$ for colder and warmer settings.

Finally, we emphasise that grain size is an important determinant of frost susceptibility (Chamberlain, 1981; Harris et al., 1993), and our results are applicable mainly to finegrained (silt-sized) sediment. Furthermore, the creep mechanism quantified by our model is likely restricted to gentle slopes of less than $15-20^{\circ}$. Other processes, such as gelifluction and debris flows, may take over at steeper slopes, resulting in more non-linear relations between slope and sediment flux (Harris et al., 1993).

\subsection{Limits to water availability?}

Whether it is necessary to penalise frost-cracking intensity according to water availability remains an open question. On the one hand, some water is always available in a porous media even at sub-zero temperatures. The water is drawn to the zone of potential frost cracking provided that a hydraulic connection exists via a film of unfrozen water along grain boundaries (pre-melted films). The temperature gradient determines the flow rate of water because it scales the suction force. However, the thickness of pre-melted films gradually decreases when temperature is lowered.

On the other hand, experimental results suggest that a nearby water source $\left(T>0{ }^{\circ} \mathrm{C}\right)$ increases frost-cracking intensity significantly (Matsuoka, 2001), which indicates that the distance between the FCW and a water source is of importance. A possible reason is that the hydraulic connection needed to maintain the suction force is less likely to be preserved over great distances if permeability is low. From this perspective, the flow-resistance parameter of our model can be seen as a measure of the number of hydraulic connections between the site of ice segregation and the site of available water. Low-permeability materials should therefore be assigned higher flow-resistance values $(\gamma)$ if following this reasoning.

However, as the discussion above highlights, this element of our model for frost cracking is unfortunately not well constrained. We have therefore striven to explore this issue as openly as possible, but further research is required to fully elucidate the influence of permeability on frost cracking.

\section{Conclusions}

We present a one-dimensional thermal model that quantifies sediment production via frost cracking of bedrock and sediment transport via frost creep, as functions of mean annual temperature and sediment thickness. The key findings are as follows:

1. The relation between MAT and frost cracking is strongly modulated by the thickness of a sediment layer. For negative MATs (in the range -10 to $-4{ }^{\circ} \mathrm{C}$ ) frostcracking intensity is enhanced by the presence of a sediment cover, whereas sediment dampens frost cracking significantly for moderately positive MATs $\left(0-9^{\circ} \mathrm{C}\right)$.

2. Whereas frost-cracking intensity peaks at MATs well above and below the freezing point, frost transport is 
most intense at MATs close to the freezing point of water. This offset may have important implications for the evolution of hillslopes in periglacial landscapes (an effect explored by Egholm et al., 2015).

3. The present model for frost cracking and frost creep is driven by temperature variations in the subsurface, whereas variations in the presence of moisture - another prerequisite for frost-driven processes - is neglected. Any systematic deviations in moisture supply or subsurface permeability should be taken into account before transferring the model to specific natural systems.

\section{The Supplement related to this article is available online at doi:10.5194/esurf-3-447-2015-supplement.}

Author contributions. J. L. Andersen and D. L. Egholm designed the study, developed the model code, performed the simulations, and produced the figures. J. L. Andersen prepared the manuscript with contributions from all co-authors.

Acknowledgements. We thank R. S. Anderson, J. Roering, T. C. Hales, and S. H. Brocklehurst for constructive reviews that greatly improved the manuscript. We also thank Jill Marshall for a fruitful discussion of penalties to water flow, which contributed to our understanding of the topic and is reflected in the discussion section of this paper. This work was supported by the Danish Council for Independent Research. J. D. Jansen was supported by a Discovery Grant from the Australian Research Council (DP130104023).

Edited by: J. Braun

\section{References}

Amitrano, D., Gruber, S., and Girard, L.: Evidence of frost-cracking inferred from acoustic emissions in a high-alpine rock-wall, Earth Planet. Sc. Lett., 341, 86-93, 2012.

Anderson, R. S.: Near-surface thermal profiles in alpine bedrock: implications for the frost weathering of rock, Arctic Alpine Res., 30, 362-372, 1998.

Anderson, R. S.: Modeling the tor-dotted crests, bedrock edges, and parabolic profiles of high alpine surfaces of the Wind River Range, Wyoming, Geomorphology, 46, 35-58, 2002.

Anderson, R. S., Anderson, S. P., and Tucker, G. E.: Rock damage and regolith transport by frost: an example of climate modulation of the geomorphology of the critical zone, Earth Surf. Proc. Land., 38, 299-316, doi:10.1002/esp.3330, 2012.

Bartlett, Marshall G., Chapman, David S., and Harris, Robert N.: Snow and the ground temperature record of climate change, J. Geophys. Res. (2003-2012), 109, F04008, doi:10.1029/2004JF000224, 2004.
Braun, J., Heimsath, A. M., and Chappell, J.: Sediment transport mechanisms on soil-mantled hillslopes, Geology, 29, 683-686, 2001.

Briner, J. P. and Swanson, T. W.: Using inherited cosmogenic ${ }^{36} \mathrm{Cl}$ to constrain glacial erosion rates of the Cordilleran ice sheet, $\mathrm{Ge}-$ ology, 26, 3-6, 1998.

Carson, M. A. and Kirkby, M. J.: Hillslope Form and Process, vol. 475, Cambridge University Press, Cambridge, 1972.

Chamberlain, E. J.: Frost susceptibility of soil, review of index tests, Tech. rep., DTIC Document, 1981.

Davison, C.: On the creeping of the soilcap through the action of frost, Geol. Mag., 6, 255-261, 1889.

Dietrich, W. E., Reiss, R., Hsu, M.-L., and Montgomery, D. R.: A process-based model for colluvial soil depth and shallow landsliding using digital elevation data, Hydrol. Process., 9, 383-400, 1995.

Egholm, D. L., Andersen, J. L., Knudsen, M. F., Jansen, J. D., and Nielsen, S. B.: The periglacial engine of mountain erosion - Part 2: Modelling large-scale landscape evolution, Earth Surf. Dynam., 3, 463-482, doi:10.5194/esurf-3-463-2015, 2015.

Fabel, D., Stroeven, A. P., Harbor, J., Kleman, J., Elmore, D., and Fink, D.: Landscape preservation under Fennoscandian ice sheets determined from in situ produced ${ }^{10} \mathrm{Be}$ and ${ }^{26} \mathrm{Al}$, Earth Planet. Sc. Lett., 201, 397-406, 2002.

French, H. M.: The Periglacial Environment, John Wiley \& Sons, West Sussex, England, UK, 2013.

Gilbert, G.: Report on the geology of the Henry Mountains, US Geographical and Geological Survey, Washington Government Printing Office, USA, Rocky Mountain Region, 1877.

Girard, L., Gruber, S., Weber, S., and Beutel, J.: Environmental controls of frost cracking revealed through in situ acoustic emission measurements in steep bedrock, Geophys. Res. Lett., 40, 17481753, 2013.

Goodfellow, B.: Relict non-glacial surfaces in formerly glaciated landscapes, Earth-Sci. Rev., 80, 47-73, 2007.

Hales, T. and Roering, J. J.: Climate-controlled variations in scree production, Southern Alps, New Zealand, Geology, 33, 701-704, 2005.

Hales, T. and Roering, J. J.: Climatic controls on frost cracking and implications for the evolution of bedrock landscapes, J. Geophys. Res., 112, F02033, doi:10.1029/2006JF000616, 2007.

Hales, T. and Roering, J. J.: A frost "buzzsaw" mechanism for erosion of the eastern Southern Alps, New Zealand, Geomorphology, 107, 241-253, 2009.

Hall, K. and Thorn, C.: The historical legacy of spatial scales in freeze-thaw weathering: misrepresentation and resulting misdirection, Geomorphology, 130, 83-90, 2011.

Hallet, B., Walder, J., and Stubbs, C.: Weathering by segregation ice growth in microcracks at sustained subzero temperatures: verification from an experimental study using acoustic emissions, Permafrost Periglac., 2, 283-300, 1991.

Harris, C., Gallop, M., and Coutard, J.-P.: Physical modelling of gelifluction and frost creep: Some results of a large-scale laboratory experiment, Earth Surface Proc. Land., 18, 5, 383-398, 1993.

Heimsath, A. M., Dietrich, W. E., Nishiizumi, K., and Finkel, R. C.: The soil production function and landscape equilibrium, Nature, 388, 358-361, 1997. 
Heimsath, A. M., Furbish, D. J., and Dietrich, W. E.: The illusion of diffusion: field evidence for depth-dependent sediment transport, Geology, 33, 949-952, 2005.

Humphreys, G. S. and Wilkinson, M. T.: The soil production function: a brief history and its rediscovery, Geoderma, 139, 73-78, 2007.

Johnstone, S. A. and Hilley, G. E.: Lithologic control on the form of soil-mantled hillslopes, Geology, 43, 83-86, 2015.

Legates, D. R. and Willmott, C. J.: Mean seasonal and spatial variability in global surface air temperature, Theor. Appl. Climatol., 41, 11-21, 1990.

Ling, F. and Zhang, T.: A numerical model for surface energy balance and thermal regime of the active layer and permafrost containing unfrozen water, Cold Reg. Sci. Technol., 38, 1-15, 2004.

Marquette, G. C., Gray, J. T., Gosse, J. C., Courchesne, F., Stockli, L., Macpherson, G., and Finkel, R.: Felsenmeer persistence under non-erosive ice in the Torngat and Kaumajet mountains, Quebec and Labrador, as determined by soil weathering and cosmogenic nuclide exposure dating, Can. J. Earth Sci., 41, 19-38, 2004.

Matsuoka, N.: The rate of bedrock weathering by frost action: field measurements and a predictive model, Earth Surf. Proc. Land., 15, 73-90, 1990.

Matsuoka, N.: Microgelivation versus macrogelivation: towards bridging the gap between laboratory and field frost weathering, Permafrost Periglac., 12, 299-313, 2001.

Matsuoka, N.: Frost weathering and rockwall erosion in the southeastern Swiss Alps: long-term (1994-2006) observations, Geomorphology, 99, 353-368, 2008.

Munroe, J. S.: Investigating the spatial distribution of summit flats in the Uinta Mountains of northeastern Utah, USA, Geomorphology, 75, 437-449, 2006.

Murton, J. B., Peterson, R., and Ozouf, J.-C.: Bedrock fracture by ice segregation in cold regions, Science, 314, 1127-1129, 2006.
Nielsen, S. B., Gallagher, K., Leighton, C., Balling, N., Svenningsen, L., Jacobsen, B. H., Thomsen, E., Nielsen, O. B., Heilmann-Clausen, C., Egholm, D. L., Summerfield, M. A., Clausen, O. R., Piotrowski, J. A., Thorsen, M. R., Huuse, M., Abrahamsen, N., King, C., and Lykke-Andersen, H.: The evolution of western Scandinavian topography: a review of Neogene uplift versus the ICE (isostasy-climate-erosion) hypothesis, J. Geodyn., 47, 72-95, 2009.

Rempel, A. W., Wettlaufer, J., and Worster, M.: Premelting dynamics in a continuum model of frost heave, J. Fluid Mech., 498, 227-244, 2004.

Sass, O.: Rock moisture measurements: techniques, results, and implications for weathering, Earth Surf. Proc. Land., 30, 359-374, 2005.

Scherler, D.: Climatic limits to headwall retreat in the Khumbu Himalaya, eastern Nepal, Geology, 42, 1019-1022, 2014.

Small, E. E. and Anderson, R. S.: Pleistocene relief production in Laramide mountain ranges, western United States, Geology, 26, 123-126, 1998.

Stroeven, A., Harbor, J., Fabel, D., Kleman, J., Hättestrand, C., Elmore, D., Fink, D., and Fredin, O.: Slow, patchy landscape evolution in northern Sweden despite repeated ice-sheet flaciation, Geol. S. Am. S., 398, 387-396, 2006.

Taber, S.: Frost heaving, J. Geol., 37, 428-461, 1929.

Vlahou, I. and Worster, M. G.: Ice growth in a spherical cavity of a porous medium, J. Glaciol., 56, 271-277, 2010.

Walder, J. and Hallet, B.: A theoretical model of the fracture of rock during freezing, Geol. Soc. Am. Bull., 96, 336-346, 1985.

Walder, J. S. and Hallet, B.: The physical basis of frost weathering: toward a more fundamental and unified perspective, Arctic Alpine Res., 18, 27-32, 1986.

Wilkinson, M. T., Chappell, J., Humphreys, G. S., Fifield, K., Smith, B., and Hesse, P.: Soil production in heath and forest, Blue Mountains, Australia: influence of lithology and palaeoclimate, Earth Surf. Proc. Land., 30, 923-934, 2005. 